\title{
A Comparison of the Anaerobic Power in Sub-Elite Male Racket and Futsal Players
}

\author{
Y1ld1z Yaprak (Corresponding author) \\ Physical Education and Sports Department \\ Hatay Mustafa Kemal University, Hatay, Turkey \\ Tel: 90-326-245-5215Ｅ-mail: yildizcyaprak@gmail.com
}

Received: May 12, 2020 Accepted: June 11, 2020 Published: June 21, 2020

doi:10.5296/jei.v6i1.17022ＵRL: https://doi.org/10.5296/jei.v6i1.17022

\begin{abstract}
The aim of this study was to define anaerobic powers of sub-elite level racket and futsal players playing at university teams and to make comparison whether there was a difference between two groups or not. 12 racket (age: 19.83 $\pm 1.02 \mathrm{yr}$ ) and 10 futsal players (age: $20.80 \pm 0.91 \mathrm{yr}$ ), 22 male players in total, voluntarily took part in this study. Body composition, Wingate anaerobic power test (WAnT), vertical jump, Illinois agility, handgrip strength and isokinetic leg strength measurements of the participants were carried out. SPSS 22.0 was used for data analysis and "Independent Samples T test" was used for comparing the data. Relative peak power (RPP) was as $12.04 \mathrm{~W} / \mathrm{kg}, 11.41 \mathrm{~W} / \mathrm{kg}$ in racket and futsal players respectively, at WAnT. And for the strength test, isokinetic extensor strength was measured as 220.61 Nm, and 217.40 Nm, isokinetic flexor strength as $134.82 \mathrm{Nm}$ and $126.28 \mathrm{Nm}$. Dominant (D) and non-dominant (ND) handgrip strength measurements of the participants were detected as $51.51 \mathrm{~kg} / \mathrm{f}$ and $49.58 \mathrm{~kg} / \mathrm{f}$ in racket sports players, as $43.42 \mathrm{~kg} / \mathrm{f}$ and 41.37 $\mathrm{kg} / \mathrm{f}$ in futsal players respectively. The difference between these variables was found statistically significant only at D $(p=.009)$ and ND $(p=.004)$, handgrip strength parameters, the difference in other variables was not found significant. As a consequence, although WAnT, handgrip and isokinetic leg strength of racket sports players were found higher than futsal players, only the difference between handgrip strengths was statistically significant. This result showed us that there was no statistical difference between anaerobic strength parameters of racket and futsal players except for handgrip strengths.
\end{abstract}

Keywords: Racket sports, Futsal, Anaerobic power, Isokinetic strength, Wingate anaerobic power test, Illinois agility test 


\section{Introduction}

Energy comprises by usage of various fuels with engagement of both aerobic and anaerobic systems. The work capacity generated by muscles by using their anaerobic energy transfer systems during maximal and supra-maximal physical activity is expressed as "anaerobic capacity" and value of this work in unit time as "anaerobic power". Anaerobic power is one of the determinant factors of performance for lots of sport branches (Plowman \& Smith, 2008; Carling et al., 2009).

Futsal is an intermittent, severe and rapidly played team sport having high physical, technical and tactical characteristics. Repeated sprints, accelerations, sudden stops, and changes of direction during the match require the players to have good aerobic, anaerobic and neuromuscular systems (Barbero-Alvarez et al., 2008; Castagna et al., 2009; Nogueira et al., 2018). Because work:rest ratio in futsal is approximately $1: 1$. Besides, futsal necessitates more agility and sprint performance than football, however less vertical jump. That the total distance logged at high intensity and maximum speed during the game in futsal is more than football, basketball and handball, and the fact that it represents the high intensity nature of futsal, was indicated (Barbero-Alvarez et al., 2008). Hearth rates (HR) of futsal players were found to be similar to tennis (Fernandez-Fernandez et al., 2009) and badminton (Faude et al., 2007) for most of the playing time and their max.HRs were found above $80 \%$. The fact that $\mathrm{HR}$ to be high during the game is estimated as a result of anaerobic metabolism (Barbero-Alvarez et al., 2008). And their average blood lactate levels were measured above $5.3 \mathrm{mmol}$ (Castagna et al., 2009). There exists quite a lot aerobic (Barbero-Alvarez et al., 2008; Castagna et al., 2009) and anaerobic (de Souza et al., 2014; Kassiano et al., 2019) performance measurements, detections of fatigue and lactate levels (Barbero-Alvarez et al., 2008), biochemical studies (Nogueira et al., 2018), elite and sub-elite comparisons (Ramos Campo et al., 2016), biomechanical studies (Barbero-Alvarez et al., 2008) and training models about futsal players in literature. Comparisons were made with football, handball (de Souza et al., 2014) and basketball (Ramos-Campo et al., 2014) in general which are team sports similar to futsal.

Racket sports require a unique combination of aerobic and anaerobic condition, speed, strength, agility, flexibility, reaction time, eye-hand coordination and technical skill (Lees, 2003; Roetert \& Ellenbecker, 2007). Racket sports are the branches in which scoring point is aimed by sending the ball, unique to that branch, with a racket to downfield with rallies between two (or four) persons. Rally period is averagely between 5-10 sec in tennis and badminton, being the most popular racket sports (Cabello Manrique \& Gonzalez-Badillo, 2003; Faude et al., 2007), apart from the duration of the match is generally between 20-90 min, it can also lengthen up till 5 hours as in the tennis. Anaerobic energy is on in the rate of $32 \%$ in tennis (Lees, 2003) and \%30 in badminton (Andersen et al., 2007) during the match; however this rate increases up to $95 \%$ in strong shots to ball (Lees, 2003). Work:rest ratio is between 1:2 and 1:5 (Kovacs, 2007) in high level tennis matches and 1:2 in badminton (Faude et al., 2007). Besides lactate level of the players' being around 3-5 mmol in rackets sports during the match, blood lactate concentration was seen to increase during severe competition and especially towards the end of the match (Cabello Manrique \& 


\section{MInstitute Macrothink}

Gonzalez-Badillo, 2003). Tennis is indicated as an aerobic based sport branch due to the fact that duration of the game is long and HR level of the players is in mid-range. Though, in order to perform effective services and send the groundstrokes effectively, it requires high anaerobic capacity (Kovacs, 2007; Roetert \& Ellenbecker, 2007).

In lots of sports like racket sports in which there is gripping and force using, enough gripping strength is needed in order for preventing injuries and catching optimal performance (Roetert \& Ellenbecker, 2007; Cronin et al., 2017). Additionally, leg strength is significant in racket sports too, as in lots of sport branches. Strength, explosive power and flexibility of the leg muscles are essential in badminton to reach maximal speed in the court, to perform lunge attacks, to perform jump overhead strokes and smashes (Ganeshkumar \& Senthilkumar, 2019).

There exist studies about racket sports in the literature such as: elite, sub-elite comparisons (Docherty, 1982; Lees, 2003), comparisons of branches forming racket sports with one another (Girard \& Millet, 2008), biomechanical analyses and various performance measurements (Elliot, 2006) or training models (Fernandez-Fernandez et al., 2012).

Racket sports are individual and futsal is a team sport. While striking the ball is performed by using upper extremity via a racket in racket sports, shots are performed directly with foot in futsal. In general, same style sport branches are used in the studies conducted in a form of comparison. With this study, even though they are in intermittent form and their game durations are similar, different branches, in which different body parts are active, were desired to be compared. The purpose of this study is to define anaerobic powers of sub-elite level racket athletes and futsal players playing at university teams and to make comparison whether there is a difference between two groups or not.

\section{Method}

\subsection{Research Group}

12 racket sports players (badminton and tennis) and 10 futsal players (total 22 male players) at sub-elite level who are at university teams and have been training 3 days a week (Sports age: Racket players $3.12 \pm 0.74 \mathrm{yr}$, Futsal players $3.70 \pm 0.82 \mathrm{yr}$ ) took part in this study voluntarily. All the subjects were informed about the study protocol, the risks of tests, and their rights according to the Declaration of Helsinki. Each participants gave written informed consent before the start of the study.

\subsection{Measurements}

The measurements lasted for 3 days (Figure 1). The measurements order were as follows: On the 1st day, body composition, vertical jump and isokinetic leg strength; on the 2nd day, isometric handgrip strength and Illinois agility test; and on the 3rd day, WAnT. All the measurements were carried out between 10-12 a.m. 
12 Racket Sports Players

10 Futsal Players

\begin{tabular}{|c|} 
1. Day \\
- Body Composition \\
Warm-up and Streching \\
- Vertical Jump \\
- Isokinetic Leg Strength
\end{tabular}

2. Day

Warm-up and Streching

- Isometric Handgrip Strength

- Illinois Agility Test

Figure 1. Experimental design

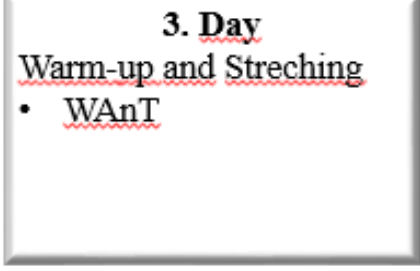

Body Composition Measurement: After height measurement was performed (SECA, Germany), bioelectric impedance method (Tanita-BC $418 \mathrm{MA}$ ) was used for identification of body composition and weight, body mass index $\left(\mathrm{BMI} \mathrm{kg} / \mathrm{m}^{2}\right)$, body fat percentage $(\mathrm{BF} \%)$, fat-free mass (FFM), dominant arm fat percentage (D-AM \%), non-dominant arm fat percentage (ND-AF \%), dominant leg fat percentage (D-LF \%), and non-dominant leg fat percentage (ND-LF \%) were noted down.

WAnT: The anaerobic power output was determined using the Monark cycle ergometer (Monark Ergomedics 894 E, Pike Byke, Finland). The participants were given detailed information about the test and they were ensured to warm-up 5 min in 60-70 $\mathrm{W}$ workload. The participants were allowed to pedal with empty load for $5 \mathrm{sec}$ to let them accelerate and asked to pedal as fast as possible for $30 \mathrm{~s}$ against a braking force that was determined by the product of body weight in $\mathrm{kg}$ by 0.075 until the end of the test. The players were motivated verbally during the test. This test was applied once and PP, RPP, and AP parameters were considered (Plowman \& Smith, 2008).

Vertical Jump Test: Vertical jump height was determined using an electronic timing mat (Just Jump System, Probotics, Inc., Huntsville, AL) that calculated jump from the time in air of the participants. After "single jump" mode was set, the participant stepped up onto the jumping mat and twisted the knees 90 degrees. Hands remained on the hips for the entire movement to eliminate any influence of arm swing. Participants jumped once in force with the command and fell on the mat again. The measurement was performed three times and only better result was noted down in $\mathrm{cm}$ (Plowman \& Smith, 2008).

Illinois Agility Test: This agility test course was marked by cones, with four center cones spaced $3.3 \mathrm{~m}$ apart and four corner cones positioned $2.5 \mathrm{~m}$ from the center cones. Firstly, the participants started lying face down with the hands at shoulder level. After that, with the "go" command, the participants got up and sprinted at the test racecourse. The participants were ensured to do trial in accordance with the test procedure and then real test score was recorded with chronometer (Miller et al., 2006).

Isokinetic Leg Strength Measurement: After the warmed-up on treadmill for 10 min in $6 \mathrm{~km} / \mathrm{h}$ 


\section{Macrothink

speed, and static stretching, participants were seated on an isokinetic dynamometer (Biodex system 3 dynamometer). The dominant limb which the knee joint angle as 90 degrees was positioned with the lateral femoral condyle aligned with the axis of rotation of the lever arm of the dynamometer. After the device's calibration, test was performed in 60 degrees/second $(\% / s)$ with 5 sets by applying Con-Con test protocol. Extensor and flexor muscles' peak torque values $(\mathrm{Nm})$ and agonist/antagonist ratio were evaluated at the end of the test performed (De lira et al., 2017).

Handgrip Strength Measurement: Digital hand dynamometer (Grip-D, Takei, Japan) was used for the determination of the isometric handgrip strengths of the participants. Once handgrip dynamometer was adjusted to the size of the player's hands, each participant performed maximal force to on standing upright position. The measurement was performed 3 times for dominant hand (D) and non-dominant hand (ND) and best value was noted down (Heyward, 2018).

\subsection{Analysis of Data}

Standard descriptive statistics were obtained (mean and standard deviation) for all variables using SPSS 22.0 version. The normality of the distribution of variables and homogeneity of variance were checked using the Kolmogorov-Smirnov test. Independent $t$ tests were conducted to determine differences between groups for parameters and confidence interval was considered as 0.05 .

\section{Results}

In the Table1, physical and anthropometric measurements of racket and futsal players participated in the study are shown. There are significant differences age $(p=.032)$ and height $(\mathrm{p}=.017)$ values between two groups. Body composition values of the racket players and futsal players were respectively detected as BF values $12.98 \%, 11.71 \%$, FFM values $61.59 \mathrm{~kg}, 61.50 \mathrm{~kg}$, trunk fat values $13.51 \%, 12.71 \%$, D-AF values $15.01 \%, 13.63 \%$, ND-AF values $16.18 \%, 13.30 \%$, D-LF values $11.24 \%$, 9.50\%, and ND-LF values $12.27 \%, 10.40 \%$. Although there is a difference in body composition values between the 2 groups, this difference is not statistically significant. 
Table 1. Physical and anthropometric parameters of racket and futsal players

\begin{tabular}{|l|l|l|l|}
\hline \multirow{2}{*}{ Parameters } & Racket Players (12) & Futsal Players (10) & \\
\cline { 2 - 4 } & Mean \pm SD & Mean \pm SD & p \\
\hline Age $(\mathrm{yr})$ & $19.83 \pm 1.02$ & $20.80 \pm 0.91$ &. $\mathbf{0 3 2}{ }^{*}$ \\
\hline Height $(\mathrm{cm})$ & $176.55 \pm 2.60$ & $172.60 \pm 3.97$ &. $\mathbf{0 1 7} *$ \\
\hline Weight $(\mathrm{kg})$ & $69.63 \pm 7.46$ & $69.91 \pm 5.71$ & .970 \\
\hline BMI $\left(\mathrm{kg} / \mathrm{m}^{2}\right)$ & $22.72 \pm 2.19$ & $22.75 \pm 1.73$ & .927 \\
\hline BF $(\%)$ & $12.98 \pm 5.55$ & $11.71 \pm 4.28$ & .592 \\
\hline FFM $(\mathrm{kg})$ & $61.59 \pm 5.55$ & $61.50 \pm 4.15$ & .973 \\
\hline Trunk Fat \% & $13.51 \pm 6.23$ & $12.71 \pm 4.79$ & .764 \\
\hline D-AF \% & $15.01 \pm 4.42$ & $13.63 \pm 2.77$ & .440 \\
\hline ND-AF \% & $16.18 \pm 5.11$ & $13.30 \pm 4.20$ & .209 \\
\hline D-LF \% & $11.24 \pm 4.49$ & $9.50 \pm 3.63$ & .378 \\
\hline ND-LF \% & $12.27 \pm 4.55$ & $10.40 \pm 3.00$ & .318 \\
\hline
\end{tabular}

Note. ${ }^{*} \mathrm{p}<0.05$. BMI: Body Mass Index, BF: Body Fat, FFM: Fat Free Mass, D-AF: Dominant Arm Fat, ND-AF: Non-dominant Arm Fat, D-LF: Dominant Leg Fat, ND-LF: Non-dominant Leg Fat. 


\section{Macrothink}

Table 2. Isokinetic leg strength $(60 \%)$, WAnT, jump, and Illinois agility test values of the racket and futsal players

\begin{tabular}{|l|l|l|l|}
\hline \multirow{2}{*}{ Parameters } & Racket Players (12) & Futsal Players (10) & \\
\cline { 2 - 4 } & Mean \pm SD & Mean \pm SD & p \\
\hline Jump $(\mathrm{cm})$ & $53.45 \pm 6.68$ & $53.69 \pm 6.19$ & .935 \\
\hline Illinois Agility Test $(\mathrm{sec})$ & $16.44 \pm 0.87$ & $16.19 \pm 0.47$ & .482 \\
\hline Isokinetic Extensor Strength $(\mathrm{Nm})$ & $220.61 \pm 23.64$ & $217.40 \pm 29.12$ & .796 \\
\hline Isokinetic Flexor Strength $(\mathrm{Nm})$ & $134.82 \pm 19.36$ & $126.28 \pm 6.65$ & .279 \\
\hline Relative Extensor Strength $(\mathrm{Nm} / \mathrm{kg})$ & $3.18 \pm 0.28$ & $3.13 \pm 0.41$ & .766 \\
\hline Relative Flexor Strength $(\mathrm{Nm} / \mathrm{kg})$ & $1.95 \pm 0.34$ & $1.82 \pm 0.19$ & .372 \\
\hline H:Q Ratio & $0.61 \pm 0.10$ & $0.58 \pm 0.07$ & .554 \\
\hline Wingate PP $(\mathrm{W})$ & $859.75 \pm 97.69$ & $763.55 \pm 114.84$ & .051 \\
\hline Wingate RPP $(\mathrm{W} / \mathrm{kg})$ & $12.04 \pm 1.71$ & $11.41 \pm 1.50$ & .399 \\
\hline Wingate AP $(\mathrm{W} / \mathrm{kg})$ & $8.45 \pm 0.79$ & $8.48 \pm 0.87$ & .948 \\
\hline
\end{tabular}

Isokinetic leg strength measurement, WAnT, jump and agility tests results are seen in Table 2. Leg extensor and flexor muscle strength measured with isokinetic dynamometer are 220.61 $\mathrm{Nm}, 134.82 \mathrm{Nm}$ in racket sports players and $217.40 \mathrm{Nm}, 126.28 \mathrm{Nm}$ in futsal players respectively. But these differences were not statistically significant between two groups. When WAnT results were analyzed, PP values on sub-elite racket and futsal players were measured as $859.75 \mathrm{~W}, 763.55 \mathrm{~W}$; RPP values as $12.04 \mathrm{~W} / \mathrm{kg}, 1.41 \mathrm{~W} / \mathrm{kg}$; AP values as 8.45 $\mathrm{W} / \mathrm{kg}, 8.48 \mathrm{~W} / \mathrm{kg}$. As shown in Table 2, no significant differences between these parameters belonging to two groups.

As shown in Figure 2, dominant handgrip strength test was detected as $51.51 \mathrm{~kg} . \mathrm{f}$ and 43.42 kg.f in racket players and futsal players respectively, and non-dominant handgrip strength test as $49.58 \mathrm{~kg}$.f and $41.37 \mathrm{~kg}$.f as. While racket players are $8 \mathrm{~kg}$.f better in dominant and non-dominant handgrip strength than futsal players. These differences between these parameters belonging to two groups were found statistically significant in favor of racket sports (D handgrip: $p=.009$, ND handgrip: $p=.004$ ). 


\section{Handgrip Strength (kg.f)}

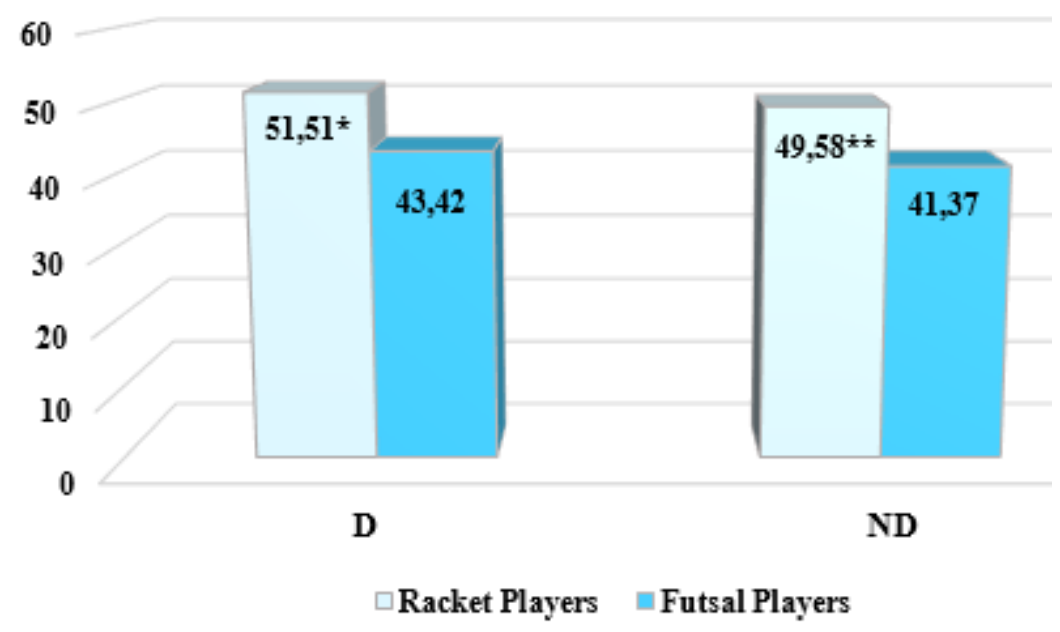

Figure 2. Dominant and non-dominant handgrip strength results of the racket players and futsal players

Note. ${ }^{*} \mathrm{p}=.009, * * \mathrm{p}=.004$. D: Dominant, ND: Non-dominant.

\section{Discussion}

Physical and anthropometric parameters of the participants in this study, which was carried out with an aim to detect anaerobic power of racket and futsal players and compare anaerobic powers of two groups, are shown in Table 1. Sudden changes of directions, attacks in front of the net, fast arm and leg motions, strong hitting in racket sports, and also sudden changes of direction, sprints and strong shots in futsal are influenced by physical and physiological structures. Racket players are approximately $4 \mathrm{~cm}$ taller than futsal players in this study and this difference is statistically significant $(\mathrm{p}=.017)$. When regional fat patterns of 2 group having similar BMI, BF\% and FFM parameters were analyzed, higher arm fat percentage was found in racket players even though they use their upper extremities predominantly. And also, their leg fat percentages are higher, too. The differences between two groups' parameters regarding their body compositions are not statistically significant. BF percentage of the tennis players were detected as $8-18 \%$ (Roetert \& Ellenbecker, 2007), for sub-elite badminton players as $10.15 \%$ average (Phomsoupha \& Laffaye, 2015) and BF \% of the futsal players between 12.70-16.45, in the literature (Ramos-Campo et al., 2014). López-Fernández et al. (2020) found D-LF and ND-LF percentages as average 11.5 in sub-elite futsal players. D-LF in futsal players was detected as $9.5 \%$ and ND-LF as $10.4 \%$ in this study.

Vertical jump and Illinois agility test results were seen to be similar when we analyzed anaerobic power tests. Agility result was determined as $16.44 \mathrm{sec}$ in racket sports and as $16.19 \mathrm{sec}$ in futsal players in this study. Agility test result of the futsal players is $25 \mathrm{split}$ seconds better. As for in the literature, Illinois agility test results were reported as average $18.50 \mathrm{sec}$ in tennis players (Rathore, 2016), as $17.66 \mathrm{sec}$ in badminton players (Wee et al., 2017), and as $17.50 \mathrm{sec}$ in futsal players (Ünveren, 2015). 
Another anaerobic power parameter vertical jump height was measured approximately as 53 $\mathrm{cm}$ in both groups and this parameter seems high when compared with the literature. Nogueira et al. (2018) found vertical jump height as $39.01 \mathrm{~cm}$ in 15 high level futsal players post-season in Brazil.

Both extensor and flexor isokinetic muscle strength of the racket athletes were higher than futsal players. Even though futsal players use lower extremities predominantly and their leg fat percentage is lower than racket athletes, the result's being low is interesting. Despite the fact that two groups' training ages, weights, BF \% and FFM parameters are similar; the reason for the difference in flexor and extensor knee muscle strength between two groups can be the kind of training performed and the rate of athletes' muscle fibril type. Strength of knee extensor and flexor muscles is significant in lots of sport branches requiring explosivity. Whilst knee extensors have a significant role in jump and kicking in futsal, knee flexors stabilize the knee while changing direction or manage running motions (Fried \& Lloyd, 1992). Speed and power of lower extremity is significant for displaying ultimate performance in tennis (Kovacs, 2006).

In the present study study, relative extensor strength parameter of the futsal players was found as $3.13 \mathrm{Nm} / \mathrm{kg}$ and their relative flexor strength parameter as $1.82 \mathrm{Nm} / \mathrm{kg}$. De lira et al (2017) also reported these parameters as $3.1 \mathrm{Nm} / \mathrm{kg}$ and $1.8 \mathrm{Nm} / \mathrm{kg}$ in professional futsal players, similar to these results. H:Q rate, indicating knee flexor and extensor muscle strength rate, was also detected as 0.61 in racket sports and as 0.58 in futsal. This rate was measured as 0.57 in Brazilian futsal players and as 0.53 in soccer players (De lira et al., 2017).

PP and RPP parameters were found higher in racket athletes in WAnT. Since flexor and extensor leg strength parameters were also found higher, WAnT results' being higher is an expected situation. Whilst RPP parameter was measured as $12.04 \mathrm{~W} / \mathrm{kg}$ in this study, RPP was detected as $10.61 \mathrm{~W} / \mathrm{kg}$ in undergraduate badminton players (Wee et al., 2017) and as 16.27 W/kg in young tennis players (Simpson et al., 2017). Whereas PP parameter of the futsal players was found as $763.55 \mathrm{~W}$ and RPP as $11.41 \mathrm{~W} / \mathrm{kg}$ in this study, in literature, Kassiano et al (2019) showed PP as $998.3 \mathrm{~W}$ and RPP as 13.2 W/kg, and De Souza et al. (2014) showed PP as $749.00 \mathrm{~W}$, and RPP as $10.76 \mathrm{~W} / \mathrm{kg}$ in young futsal players.

\section{Conclusion}

Badminton is the fastest racket sport of the World and while the speed of the ball reaches above $100 \mathrm{~m} \mathrm{~s}^{-1}$ with smash, this speed was measured as $73 \mathrm{~m} \mathrm{~s}^{-1}$ in tennis and as $62 \mathrm{~m} \mathrm{~s}^{-1}$ in soccer (Cohen \& Clanet, 2016). In order to provide optimal performance in many sports branches, such as racket sports, golf, weightlifting, hockey, baseball, in which handgrip strength is significant, an adequate handgrip strength is necessary even if not a high degree (Cronin et al., 2017). Both dominant and non-dominant handgrip strength scores are approximately $8 \mathrm{~kg}$.f more in racket sport players in the present study, and this difference between two groups was statistically significant $(p=.009$ and $p=.004)$. Besides racket's affecting the speed of the ball in racket sports, these athletes' handgrip strengths being high, depending on their always using upper extremities, is an expected situation. Because, in order to be able to perform effective services and resend groundstrokes strongly in tennis players 
and in order to be able to perform effective smash and other shots in badminton players, high grip strength is necessary (Roetert \& Ellenbecker, 2007).

As a consequence, anaerobic strengths of racket and futsal players, being two different branches, were detected in this study. Despite the fact that two different branches have similar characteristics in vertical jump, and in Illinois agility parameters; racket sport players were detected to have higher values in WAnT, handgrip strength and isokinetic leg strength parameters. However, this difference was not found statistically significant except for the D and ND handgrip strengths. In this study, an idea was obtained about the anaerobic performances of two different branch players who require similar strength, speed, agility, aerobic and anaerobic power playing in the university sports team. This results may enable us to consider and to make a comparison the anaerobic criteria when choosing athletes for the sports team.

\section{References}

Andersen, L. L., Larsson, B., Overgaard, H., \& Aagaard, P. (2007). Torque-velocity characteristics and contractile rate of force development in elite badminton players. European Journal of Sport Science, 7, 127-134. https://doi.org/10.1080/17461390701579584

Barbero-Alvarez, J. C., Soto, V. M., Barbero-Alvarez, V., \& Granda-Vera, J. (2008). Match analysis and heart rate of futsal players during competition. J Sports Sci, 26, 63-73. https://doi.org/10.1080/02640410701287289

Cabello Manrique, D., \& Gonzalez-Badillo, J. J. (2003). Analysis of the characteristics of competitive badminton. Br J Sports Med, 37, 62-66. https://doi.org/10.1136/bjsm.37.1.62

Carling, C., Williams, A., \& Reilly, T. (2009). The handbook of soccer match analysis: A systematic approach to improving performance. Abingdon: Routledge.

Castagna, C., D’Ottavio, S., Granda-Vera, J., \& Barbero-Alvarez, J. C. (2009). Match demands of professional futsal: A case study. J Sci Med Sport, 12, 490-494. https://doi.org/ 10.1016/j.jsams.2008.02.001

Cohen, C., \& Clanet, C. (2016). Physics of ball sports. Europhys News, 47(3), 13-16. https://doi.org/10.1051/epn/2016301

Cronin, J., Lawton, T., Harris, N., Kilding, A., \& McMaster, D. T. (2017). A brief review of handgrip strength and sport performance. $J$ Strength Cond Res, 31, 3187-3217. https://doi.org/10.1519/JSC.0000000000002149

De Lira, C., Mascarin, N. C., Vargas, V. Z., Vancini, R. L., \& Andrade, M. S. (2017). Isokinetic knee muscle strength profile in Brazilian male soccer, futsal and beach soccer players: A cross-sectional study. Int J Sports Phys Ther, 12, 1103-1110. https://doi.org/ 10.26603/ijspt20171103

de Souza, B. F., Ferreira, R., Fagundes, A., Kawaguchi, L., Ribeiro, W., \& Lazo-Osório, R. (2014). Analysis of anaerobic performance between futsal and handball through the Wingate test. Adv Phy Edu, 4(1), 25-8. https://doi.org/10.4236/ape.2014.41004 
Docherty, D. (1982). A comparison of heart rate responses in racquet games. Br J Sports Med, 16, 96-100. https://doi.org/10.1136/bjsm.16.2.96

Elliott, B. (2006). Biomechanics and tennis. Br J Sports Med, 40, 392-6. https://doi.org/ $10.1136 / \mathrm{bjsm} .2005 .023150$

Faude, O., Meyer, T., Rosenberger, F., Fries, M., Huber, G., \& Kindermann, W. (2007). Physiological characteristics of badminton match play. Eur J Appl Physiol, 100, 479-85. https://doi.org/10.1007/s00421-007-0441-8

Fernandez-Fernandez, J., Sanz-Rivas, D., \& Mendez-Villanueva, A. (2009). A review of the activity profile and physiological demands of tennis match play. Strength Cond J, 31, 15-26. https://doi.org/10.1519/SSC.0b013e3181ada1cb

Fernandez-Fernandez, J., Zimek, R., Wiewelhove, T., \& Ferrauti, A. (2012). High-intensity interval training vs. repeated-sprint training in tennis. J Strength Cond Res, 26, 53-62. https://doi.org/10.1519/JSC.0b013e318220b4ff

Fried, T., \& Lloyd, G. (1992). An overview of common soccer injuries. Management and prevention. Sport Med, 14, 269-275. https://doi.org/10.2165/00007256-199214040-00005

Ganeshkumar, T., \& Senthilkumar, P. K. (2019). Efficacy of specific skill and neuromuscular training on speed and explosive power among badminton players. International Journal of Physiology, Nutrition and Physical Education, 4(1), 1455-1457.

Girard, O., \& Millet, G. P. (2008). Neuromuscular fatigue in racquet sports. Neurologic Clin, 26(1), 181-94. https://doi.org/10.1016/j.ncl.2007.11.011

Heyward, V. H. (2018). Advanced fitness assessment and exercise prescription. Champaign, IL: Human Kinetics.

Kassiano, W., Andrade, A. D., de Jesus, K., Lima, A. B., Simim, M. A., Medeiros, A. I., \& Assumpção, C. (2019). Neuromuscular parameters and anaerobic power of U-20 futsal players. Journal of HumanSport and Exercise, 14(1), 207-214. https://doi.org/10.14198/jhse. 2019.141.17

Kovacs, M. S. (2006). Applied physiology of tennis performance. Br J Sports Med, 40, 381-386. https://doi.org/10.1136/bjsm.2005.023309

Kovacs, M. S. (2007). Tennis physiology: Training the competitive athlete. Sports Med, 37(3), 189-98. https://doi.org/10.2165/00007256-200737030-00001

Lees, A. (2003). Science and the major racket sports: a review. J Sports Sci, 21(9), 707-732. https://doi.org/10.1080/0264041031000140275

López-Fernández, J., García-Unanue, J., Sánchez-Sánchez, J., Colino, E., Enrique Hernando, E., \& Gallardo, L. (2020). Bilateral Asymmetries Assessment in Elite and Sub-Elite Male Futsal Players. Int. J. Environ. Res. Public Health, 17, 3169. https://doi.org/10.3390/ijerph 17093169 


\section{I Macrothink}

Miller, M., Herniman, J., Ricard, M., Cheatham, C. C., \& Michael, T. J. (2006). The effects of a 6-week plyometric training program on agility. J Sports Sci Med, 5, 459-65.

Nogueira, F. D. A., de Freitas, V. H., Nogueira, R. A., Miloski, B., Werneck, F. Z., \& Bara-Filho, M. G. (2018). Improvement of physical performance, hormonal profile, recovery-stress balance and increase of muscle damage in a specific futsal preseason planning. Rev. Andal. Med. Deporte, 11(2), 63-68. https://doi.org/10.1016/j.ramd.2015.11.008

Phomsoupha, M., \& Laffaye, G. (2015). The science of badminton: Game characteristics, anthropometry, physiology, visual fitness and biomechanics. Sports Medicine, 45(4), 473-495. https://doi.org/10.1007/s40279-014-0287-2

Plowman, S. A., \& Smith, D. L. (2008). Exercise physiology for health, fitness and performance. San Francisco, CA: Benjamin Cummings

Ramos-Campo, D. J., Rubio-Arias, J. A., Carrasco-Poyatos, M., \& Alcaraz, P. E. (2016). Physical performance of elite and subelite Spanish female futsal players. Biol Sport, 33, 297-304. https://doi.org/10.5604/20831862.1212633

Ramos-Campo, D. J., Martínez-Sánchez, F., Esteban-García, P., Rubio-Arias, J. A., Bores, C. A., Clemente-Suarez, V. J., \& Jiménez-Díaz, J. F. (2014). Body Composition Features in Different Playing Position of Professional Team Indoor Players: Basketball, Handball and Futsal. International Journal of Morphology, 32(4), 1316-1324.

Rathore, M. S. (2016). Effects of Plyometric Training and Resistance Trainng on Agility of Tennis Players. Indian Journal of Physical Education, Sports Medicine \& Exercise Science, $16(1 \& 2), 32-34$.

Roetert, E. P., \& Ellenbecker, T. S. (2007). Complete Conditioning for Tennis (pp. 3-5). Champaign, IL: Human Kinetics.

Simpson, A. E., Helm, K. D., Saez, G. M., \& Smith, J. R. (2017). Anaerobic parameters of division I collegiate male and female tennis players. Journal of Exercise Physiology, 20(1), 177-187.

Ünveren, A. (2015). Investigating women futsal and soccer players' acceleration, speed and agility features. Anthropologist, 21(1-2), 361-365. https://doi.org/10.1080/09720073.2015. 11891825

Wee, H. E., Low, Y. J., Chan, Q. K., \& Ler, H. Y. (2017). Effects of high intensity intermittent badminton multi-shuttle feeding training on aerobic and anaerobic capacity, leg strength qualities and agility. Proceedings of the 5th International Congress on Sport Sciences Research and Technology Support (pp. 39-47). https://doi.org/10.5220/0006501000390047 


\section{Copyright Disclaimer}

Copyright for this article is retained by the author(s), with first publication rights granted to the journal.

This is an open-access article distributed under the terms and conditions of the Creative Commons Attribution license (http://creativecommons.org/licenses/by/3.0/). 